\title{
Post-Tuberculosis Lung Disease: Clinical Review of an Under-Recognised Global Challenge
}

\author{
Brian W. Allwood ${ }^{\mathrm{a}}$ Anthony Byrne ${ }^{\mathrm{b}}$ Jamilah Meghjic Andrea Rachow ${ }^{\mathrm{d}} \mathrm{e}$ \\ Marieke M. van der Zalm ${ }^{f}$ Otto Dagobert Schoch ${ }^{g, h}$ \\ aDivision of Pulmonology, Department of Medicine, Stellenbosch University, Stellenbosch, South Africa; \\ bHeart Lung Clinic, St Vincent's Hospital Clinical School, University of New South Wales, St. Vincent, NSW, Australia; \\ 'Department of Clinical Sciences, Liverpool School of Tropical Medicine, Liverpool, UK; dDivision of Infectious \\ Diseases and Tropical Medicine, Medical Centre of the University of Munich (LMU), Munich, Germany; \\ 'German Centre for Infection Research (DZIF), Partner Site, Munich, Germany; fDesmond Tutu TB Centre, \\ Department of Paediatrics and Child Health, Stellenbosch University, Stellenbosch, South Africa; ' Lung Center,

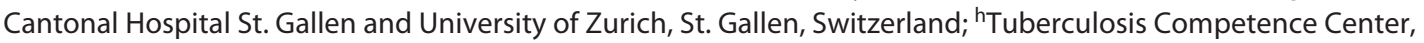 \\ Swiss Lung Association, Berne, Switzerland
}

\section{Keywords}

Post-tuberculosis lung disease $\cdot$ Chronic obstructive pulmonary disease $\cdot$ Restrictive lung disease .

Bronchiectasis · Aspergillosis · Haemoptysis

\begin{abstract}
An estimated 58 million people have survived tuberculosis since 2000, yet many of them will suffer from post-tuberculosis lung disease (PTLD). PTLD results from a complex interplay between organism, host, and environmental factors and affects long-term respiratory health. PTLD is an overlapping spectrum of disorders that affects large and small airways (bronchiectasis and obstructive lung disease), lung parenchyma, pulmonary vasculature, and pleura and may be complicated by co-infection and haemoptysis. People affected by PTLD have shortened life expectancy and increased risk of recurrent tuberculosis, but predictors of longterm outcomes are not known. No data are available on PTLD in children and on impact throughout the life course. Riskfactors for PTLD include multiple episodes of tuberculosis, drug-resistant tuberculosis, delays in diagnosis, and possibly
\end{abstract}

smoking. Due to a lack of controlled trials in this population, no evidence-based recommendations for the investigation and management of PTLD are currently available. Empirical expert opinion advocates pulmonary rehabilitation, smoking cessation, and vaccinations (pneumococcal and influenza). Exacerbations in PTLD remain both poorly understood and under-recognised. Among people with PTLD, the probability of tuberculosis recurrence must be balanced against other causes of symptom worsening. Unnecessary courses of repeated empiric anti-tuberculosis chemotherapy should be avoided. PTLD is an important contributor to the global burden of chronic lung disease. Advocacy is needed to increase recognition for PTLD and its associated economic, social, and psychological consequences and to better understand how PTLD sequelae could be mitigated. Research is urgently needed to inform policy to guide clinical decisionmaking and preventative strategies for PTLD.

(c) 2021 S. Karger AG, Basel

From the Thematic Review Series: "Tuberculosis"

Series Editors: Coenraad F. Koegelenberg, Christoph Lange, Otto D. Schoch. karger@karger.com www.karger.com/res

(C) 2021 S. Karger AG, Base

Karger ${ }^{\prime}=$
Otto Dagobert Schoch

Division of Pulmonary Medicine

Kantonsspital St. Gallen

CH-9007 St. Gallen (Switzerland)

otto.schoch@kssg.ch 


\section{Introduction}

Post-tuberculosis lung disease (PTLD) has been overlooked as a significant cause of chronic lung disease for the last 50 years. In the first half of the last century, much was written about post-tuberculosis complications. However, with the advent of effective chemotherapeutic agents to treat tuberculosis, the focus of the international tuberculosis research and clinical community shifted towards diagnostics and anti-tuberculosis treatment, with the aim of improving disease survival.

This is now changing: the last decade has seen a renewed focus on the high burden and damaging impact of the long-term sequelae of tuberculosis disease, for individual patients, their households, and their communities [1]. The first International Post-Tuberculosis Symposium was held in 2019 (www.post-tuberculosis.com) to bring together patients, clinicians, and researchers working in this area, in order to advocate for patients suffering from post-tuberculosis complications and to identify existing knowledge and evidence gaps [2,3]. PTLD was an area of particular interest at the symposium and was defined as "evidence of chronic respiratory abnormality, with or without symptoms, attributable at least in part to previous pulmonary tuberculosis."

In this review, we summarise current thinking about PTLD and highlight research priority areas. However, we caution that PTLD must be viewed as only one of several possible consequences that may occur after tuberculosis. Many other organ systems can be permanently affected by tuberculosis and may result in significant disability, and the importance of economic, social, and psychological impacts, including stigmatization, cannot be overstated.

\section{Epidemiology}

Last year, an estimated 10 million people worldwide suffered from active tuberculosis disease, and the vast majority of these cases involved the lung. Among patients who receive antimycobacterial treatment, global treatment success rates average $85 \%$, and the World Health Organisation (WHO) estimates some 58 million lives were saved through tuberculosis diagnosis and treatment between 2000 and 2018 alone [4].

Emerging data suggest a high burden of residual morbidity and mortality among tuberculosis survivors, even after treatment completion. Even in high-income countries, the observed mortality rates of tuberculosis survivors are significantly higher (3-6 times) than those of the general population [5-7]. According to Romanowski et al. [5], cardiovascular disease is the leading cause of the excess deaths after tuberculosis treatment completion, while, in contrast, a large Brazilian cohort study found respiratory disease to be the most frequent cause of excess deaths in the first year after tuberculosis diagnosis [7].

The number of PTLD-related publications has increased significantly in recent years [1] and includes data from large international population-based studies investigating the global burden of chronic respiratory diseases in low- and middle-income countries (LMICs). Taken together, there is now convincing evidence for the existence of chronic lung disease after pulmonary tuberculosis, which contributes to excess morbidity after treatment completion. Findings from the Burden of Obstructive Lung Disease (BOLD) study and the PLATINO study $[8,9]$, together with other clinical studies and systematic reviews, have consistently demonstrated an association between previous tuberculosis disease and abnormal lung structure and function [1013]. Several large, prospective cohort studies are underway, evaluating the clinical spectrum, characteristics, and severity of PTLD and its evolution over time, with their early data supporting previous findings [14].

Despite this growing body of data, accurate estimates of the global burden and morbidity associated with PTLD remain limited. Such estimates have been hampered by the diverse clinical spectrum of PTLD presentations (see below), limited correlation between physiological, radiological, symptom, and outcome data with different ways of measuring disease, and heterogeneous case definitions. Current estimates of residual spirometric abnormalities after tuberculosis vary widely according to the population under study and range from 34 to $74 \%$, with estimates for obstructive and restrictive physiology ranging from 18.4 to $86 \%$ and 16.1 to $29.7 \%$, respectively [12-15]. Spirometry alone may underestimate post-tuberculosis lung damage when measured against either radiology or extended physiology (e.g., diffusing capacity and plethysmography) $[14,16]$.

Consensus achieved at the first International Post-Tuberculosis Symposium regarding these patterns and definitions, in conjunction with a number of ongoing prospective cohorts, will hopefully help to clarify these estimates. However, even with improved definitions, post-tuberculosis patients in both high- and low-income settings are frequently exposed to multiple concurrent respiratory exposures, including smoking, cannabis use, indoor biomass fuels, and occupational exposures, such that it may remain challenging to attribute the burden of lung disease due to tuberculosis alone within this group.
Allwood/Byrne/Meghij/Rachow/ van der Zalm/Schoch 


\section{Pathogenesis}

PTLD is a result of the interplay between direct damage caused by the tuberculosis organism in the lower respiratory tract and the host immune response $[13,17]$. These processes result in airway distortion, reduced elasticity, destruction of the muscular components of bronchial walls, or damage to the lung parenchyma and vasculature, which lead to structural pathology and anatomical distortion on imaging, and abnormal respiratory physiology with abnormal spirometry, altered lung volumes and impaired diffusing capacity [17]. The host-immune relationship in tuberculosis is extremely complex and beyond the scope of this review. However, the heterogeneity of lung damage observed between pulmonary tuberculosis patients may be explained by variation in the nature and severity of the host immune response, pathogen characteristics, and the host-pathogen interaction [13]. We highlight a few key concepts relevant to the development of PTLD here.

Following inhalation, Mycobacterium tuberculosis must evade the innate immune defences of the respiratory tract in order to progress to disease. After negotiating airway epithelial cells, the organism may infect phagocytes such as dendritic cells and alveolar macrophages, where it not only survives but replicates [18]. This initiates an anti-inflammatory response that blocks reactive oxygen and nitrogen intermediate production and reduces the acidity of the phagosome, tasked with attempting to contain the bacilli [19]. The alveolar macrophage is subsequently destroyed by the escaping organisms after replication, which in turn attracts other inflammatory cells such as neutrophils. Meanwhile, antigen-presenting dendritic cells have travelled to lymph nodes by $6-8$ weeks to activate and recruit $\mathrm{T}$ lymphocytes that migrate to the site of infection to proliferate and form early granulomas [20]. The heterogeneity of lung damage observed between individuals with (treated) pulmonary tuberculosis may be explained by the host-pathogen interaction and perhaps the variability in gene coding for the complex array of host immune responses [13]. It is important to mention at this point that the prompt initiation of (effective) antituberculosis treatment may mitigate host damage by eradication of the initiating stimulus [21]. Nonetheless, despite appropriate treatment, some patients develop cavitation, bronchiectasis, fibrosis, and other irreversible structural changes. While the precise mechanisms are not yet fully understood, there are 4 important components: (1) the process of granuloma formation and resolution, (2) cytokines production including tumour necrosis fac-

Post-Tuberculosis Lung Disease tor alpha and interleukins, (3) transcription factors including hypoxia-inducible factor, and (4) enzymes such as the matrix metalloproteinases (MMP) [13]. Granulomas are complex structures containing natural killer cells, neutrophils, and $\mathrm{T}$ and $\mathrm{B}$ lymphocytes surrounding a necrotic core of infected alveolar macrophages. The granuloma may contain many or few bacilli, and rather than being protective to the host, it may aid mycobacterial proliferation and lung destruction [22]. Animal studies suggest tumour necrosis factor alpha may perpetuate necrosis; however; low levels may reduce macrophage activity [23]. The MMPs are a group of 28 different proteases implicated in lung injury and remodelling through the degradation of extracellular matrix components. Hypoxic conditions have been shown to upregulate MMP-1 via hypoxia-inducible factor, which may partly explain the greater tissue destruction seen in patients with tuberculosis disease and cavities [24]. A greater understanding of the immunopathogenesis and of the underlying genetic factors that regulate genetic factors that regulate these immune responses will lead to improved respiratory outcomes in PTLD, through integration of immune-modulating host-directed therapies in the treatment of pulmonary tuberculosis. Finally, environmental and inhaled factors (e.g., smoking) may play an as-yet undetermined modifying role in the host-pathogen interaction, worsening outcomes after treatment completion.

\section{Clinical Patterns of PTLD}

Patients after tuberculosis present with a wide range of consequences from completely asymptomatic to severe disability. PTLD is heterogeneous and includes pathology affecting the airways, parenchyma, pleural, and pulmonary vascular compartment. Multiple patterns of pathology can be seen within a single patient, between or within areas of the lung (Table 1). Post-tuberculosis bronchiectasis can range from simple traction to actual disease of the bronchi, and the natural history of this disease may be different from other forms of non-CF bronchiectasis.

\section{Airway Pathology}

Large population-based studies, systematic reviews, and clinical cohort work suggest that previous tuberculosis disease is associated with chronic airway obstruction $[8,10,11,25-29]$, reduced lung volumes $[8,15,30]$, and mixed patterns of disease. Few data are available describing the trajectory of spirometry volumes over time from the point of tuberculosis diagnosis, through to treatment 

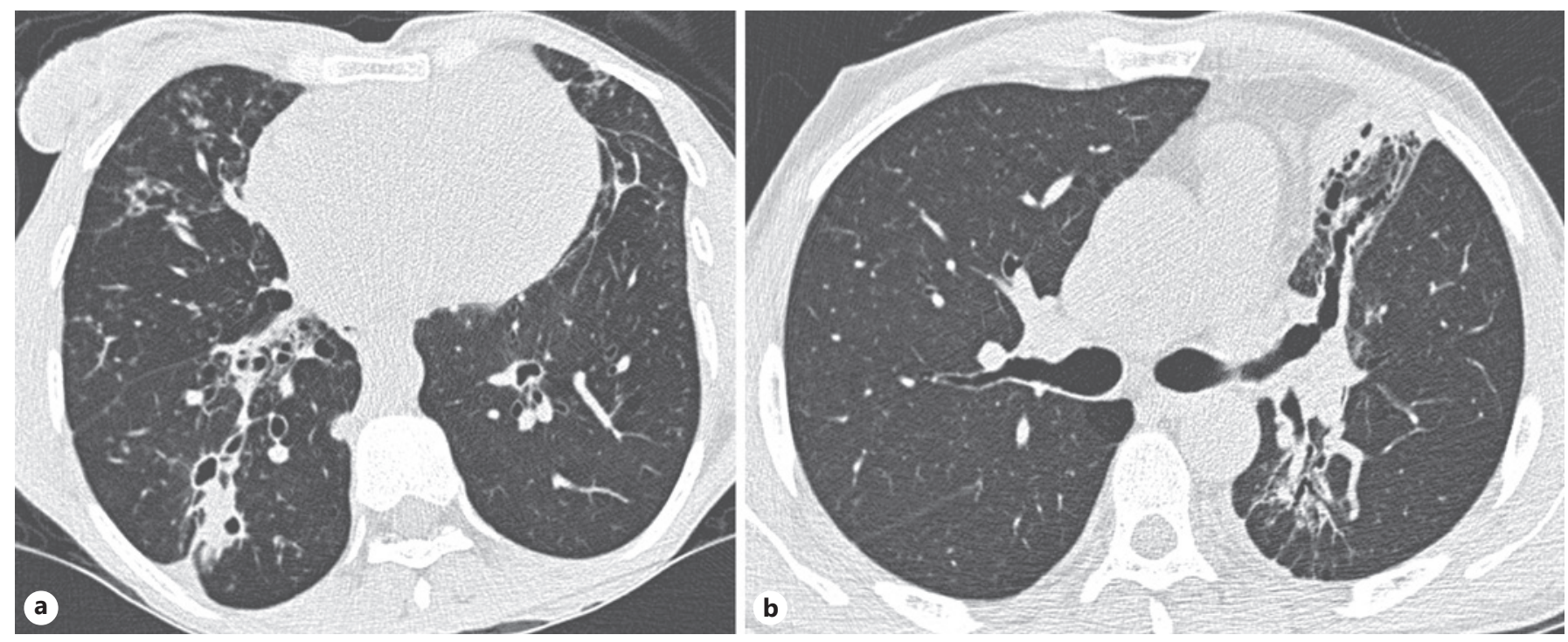

Fig. 1. Two patients with post-tuberculosis lung disease, exhibiting bronchiectasis predominantly in the right lower lobe with residual nodularity bilaterally (a) and bronchiectasis predominantly in the left upper lobe, lingula (b).

Table 1. Clinical patterns of PTLD

\begin{tabular}{|c|c|c|}
\hline Compartment & Clinical patterns & Suggested definition \\
\hline \multirow[t]{2}{*}{ Airways } & $\begin{array}{l}\text { Tuberculosis-associated obstructive } \\
\text { lung disease }\end{array}$ & $\begin{array}{l}\text { Airway obstruction (FEV1/FVC ratio }<0.7 \mathrm{OR}<\mathrm{LLN} \text { ) thought primarily related to small airway } \\
\text { disease }\end{array}$ \\
\hline & Bronchiectasis & $\begin{array}{l}\text { CT definition - evidence of airway dilatation }>\text { diameter of adjacent vessel, or non-tapering, or } \\
\text { CXR definition - evidence of ring shadows and tramlines }\end{array}$ \\
\hline \multirow[t]{4}{*}{ Parenchyma } & Cavitation & A gas-filled space either within an area of pulmonary consolidation or surrounded by a thin wall \\
\hline & Parenchymal destruction & $\begin{array}{l}\text { Extensive destruction of lung tissue, with a gas-filled space/collapsed parenchyma occupying the } \\
\text { volume of } \geq 1 \text { lobe }\end{array}$ \\
\hline & Fibrotic change & Areas of parenchymal scarring with associated volume loss \\
\hline & Aspergillus-related lung disease & $\begin{array}{l}\text { Evidence of aspergilloma on imaging or chronic pulmonary aspergillosis on imaging and blood } \\
\text { testing }\end{array}$ \\
\hline Pleural & Chronic pleural disease & Evidence of pleural thickening on CXR or CT imaging \\
\hline $\begin{array}{l}\text { Pulmonary } \\
\text { vascular }\end{array}$ & Pulmonary hypertension & $\begin{array}{l}\text { Elevated pulmonary artery pressures, as estimated using Doppler echocardiography or measured } \\
\text { at right heart catheterisation }\end{array}$ \\
\hline
\end{tabular}

PTLD, post-tuberculosis lung disease; FEV1, forced expiratory volume in $1 \mathrm{~s}$; CT, computerized tomography; CXR, chest radiograph.

completion, and into recovery, but modelling data suggest limited and incomplete recovery over time [31], and this finding is supported by emerging prospective follow-up data [14]. A recent study in a small cohort using quantitative computerized tomography (CT) imaging and plethysmography demonstrated an evolution of increased airway gas trapping, even after treatment completion [16].

\section{Structural Pathology}

There are no clinically validated tools for the description or severity scoring of structural pathology on imaging, after pulmonary tuberculosis disease. However, changes seen on chest radiographs and CT include residual cavitation, bronchiectasis, and fibrotic change, often with anatomical distortion and destroyed lung tissue 

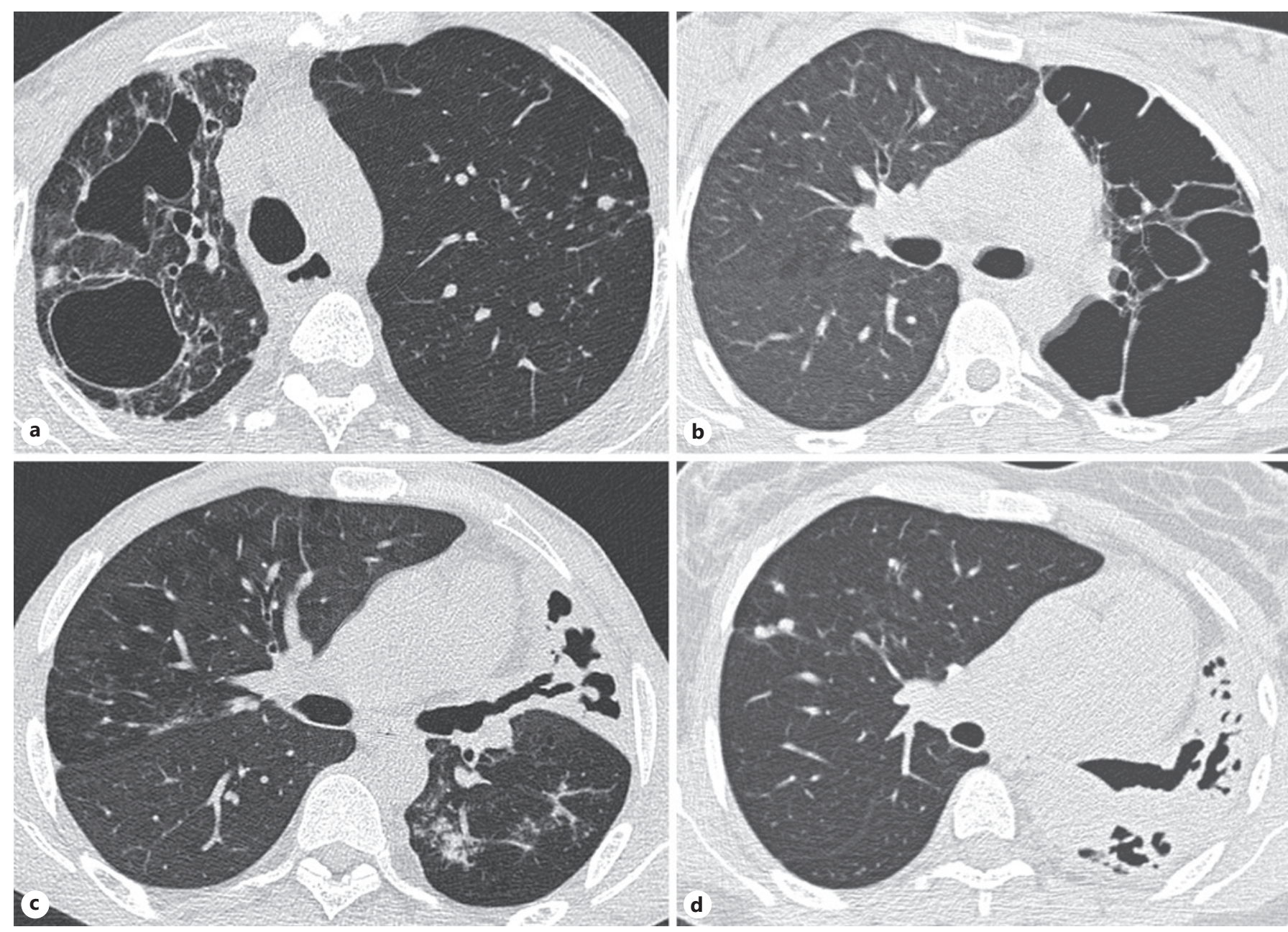

Fig. 2. Post-tuberculosis lung disease in 4 individuals demonstrating residual cavitation and bronchiectasis in the right lung, with volume loss (a); complete left lung destruction with relatively preserved left lung volume (b); mosaicism, residual nodularity and lobar destruction/collapse (c); and complete collapse of the left lung with compensatory hyperinflation $(\mathbf{d})$.

[11, 14, 32, 33] (Fig. 1, 2). A high burden of residual inflammatory changes including consolidation, ground glass change, and nodules have been observed at tuberculosis treatment completion, with metabolic activity in these lesions appearing to fluctuate over time on PET-CT imaging - the clinical significance of this ongoing inflammation is not yet clear $[34,35]$.

\section{Pulmonary Vascular Disease}

The burden of pulmonary vascular disease among the post-tuberculosis population remains poorly defined but is thought to be secondary to lung damage and may be common in the context of extensive pulmonary disease $[36,37]$, with clinicians in high-burden settings frequently encountering patients with advanced cor pulmonale.
More data on the incidence and prognostic implications of pulmonary hypertension among tuberculosis survivors are required to elucidate the pathophysiology, outcomes, and potential therapeutic options.

\section{Aspergillus-Related Disease and Haemoptysis}

Bronchiectasis and fungal diseases with subsequent haemoptysis are severe, potentially life-threatening complications after successful tuberculosis treatment, and form an important part of the PTLD spectrum. Data on the burden of aspergillosis disease among tuberculosis survivors in LMICs are limited, with mixed results, largely due to the challenge in containing the imaging, serology, and microbiology required for diagnosis. In a recent cohort of 405 survivors of a successfully treated first epi- 
sode of pulmonary tuberculosis from Malawi, examined at treatment completion with high-resolution computed tomography, some form of post-tuberculosis bronchiectasis was found in 170 (44.2\%) [14]. Moderate-to-severe cystic bronchiectasis were found in 49 patients (12.7\%), with a higher prevalence in HIV-negative (18.9\%) as compared to HIV-positive (8.5\%) patients. Mycetoma was present in $5(1.3 \%)$ patients, and Aspergillus IgG was found in $2(0.8 \%)$ [14].

After inhalation of Aspergillus species, early innate immune reaction activates alveolar macrophages and epithelial cells to trigger neutrophil recruitment and reduce fungal burden [38]. In pre-existing structural lung damage, for example, persistent cavitary lesions after healed tuberculosis, chronic necrotizing pulmonary aspergillosis with slowly progressing invasive fungal pneumonia and inflammatory necrosis are classical sequelae $[38,39]$. On a world-wide scale, it has been recognized that previous tuberculosis is by far the most common risk factor for chronic pulmonary aspergillosis (CPA), with some researchers estimating 5-year prevalence rate of $18 \%$ after tuberculosis treatment [40]; however, estimates vary widely, and evolution over time may be an important factor $[14,41,42]$. In cases of CPA, chronic inflammation leading to increased vascularization with bronchial arteries and the feared complication of profound haemoptysis and asphyxia may result. Diagnostic criteria for CPA include the presence of respiratory or constitutional symptoms for at least 3 months, suggestive radiological findings and serological or microbiological evidence of Aspergillus[43].

\section{Childhood PTLD and Lung Development}

An estimated 1.1 million children $<15$ years develop tuberculosis each year, with paediatric disease accounting for an estimated $10 \%$ of the total tuberculosis disease burden in LMICs [4]. Children $<5$ years have a high risk of disease progression following infection, with risk declining in children of primary school age ( 5 to $<10$ years) and rising again during puberty $[44,45]$, such that almost $60 \%$ of all paediatric cases of tuberculosis disease occurred in children $<5$ years of age [46]. These young children and especially those $<2$ years of age also have high risk of severe and disseminated disease $[47,48]$. Despite the high burden, there are currently no data available on the impact of tuberculosis on long-term child lung health.

Lung development starts in utero and continues through early adulthood, when lung growth plateaus [49,
50]. Data suggest that alveoli continue to increase in number, size, and complexity into early adulthood [51], and early lung insults have been shown to lead to alterations in lung growth and development and potentially permanent loss of lung function $[49,52]$. The extent to which insults to the developing lung are associated with increased risk of chronic respiratory illnesses in later life depends on the underlying cause, timing, and significance of such insults [53]. Numerous cohort studies have shown that there is an association between lung function in childhood and adulthood $[54,55]$, and lower respiratory tract infections during infancy have been shown to reduce lung function in childhood [56, 57]. A longitudinal study by Githinji and colleagues [58] in HIV-infected adolescents recently found that prior history of tuberculosis or severe lower respiratory tract infections were independently associated with consistent lower lung function trajectories. This finding suggest tuberculosis has an impact on lung function; however, prospective and more detailed data about type and severity of tuberculosis episode and its impact on lung health are required.

The pathophysiology of paediatric pulmonary tuberculosis is different from adult-type tuberculosis disease, with less destructive cavitary disease as seen in adults and adolescents. Nevertheless, paediatric pulmonary tuberculosis represents a wide disease spectrum, both in terms of severity and typical patterns, which is often related to age at disease presentation. Children may present with uncomplicated lymph node disease, complicated lymph node disease with airway compression and lobar collapse, bronchopneumonia, miliary tuberculosis, adulttype cavitary disease, pleural effusion, or a peripheral opacity with associated lymph node enlargement [59, 60]. Young infants are particularly at risk for severe intrathoracic and disseminated tuberculosis associated with increased morbidity and mortality [47, 48], while adolescents present in a manner similar to adults, with destructive pulmonary disease. The variability in disease presentation in the different age groups and the developing lung, combined with the intricacies of lung function assessment in young children, causes challenges in investigating long-term respiratory outcomes in children. Overall, tuberculosis in childhood likely has an effect on an individuals' attained lung function (i.e., lower trajectory) and potentially the rate of decline later in life (Fig. 3). This potential impact may be subclinical throughout childhood but may result in a symptomatic respiratory morbidity threshold being crossed at an early adult age $[49,61]$. Paediatric data are urgently needed to establish the burden of PTLD in children, and those should
Allwood/Byrne/Meghii/Rachow/ van der Zalm/Schoch 


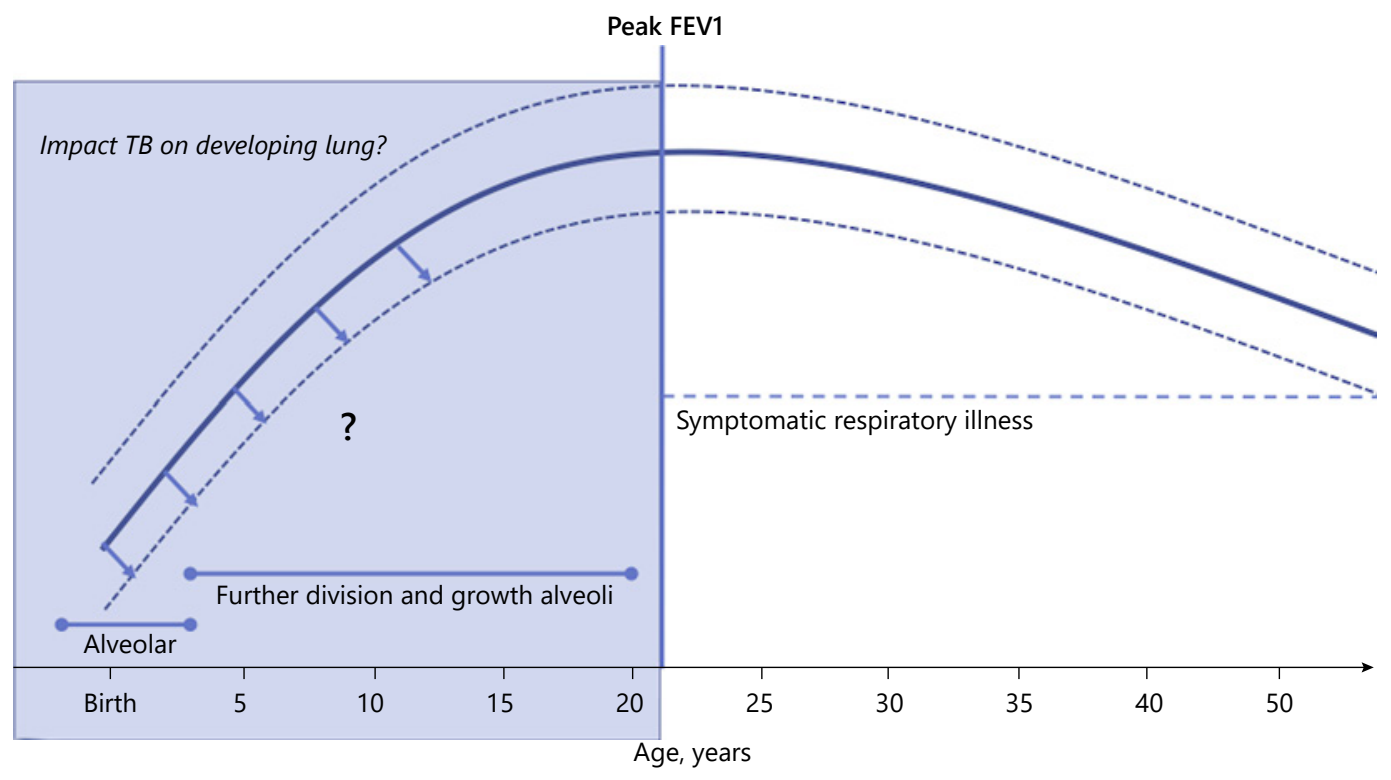

Fig. 3. Lungs develop throughout childhood until they reach a plateau around the age of 20 years. Alveoli appear from week 29 of gestation and continue to form until 2-4 years after birth. After that, alveoli continue to increase in number, size, and complexity until early adulthood. It is known that lung function tracks throughout life, meaning that it remains in similar percentile over

include lung function measurements regardless of symptoms and social determinants for lung health.

\section{Clinical Outcomes Associated with PTLD}

Prospective data on the long-term outcomes of PTLD remain limited, and no validated prognostic scores are yet available. However, cross-sectional data from tuberculosis survivors suggest a high prevalence of chronic respiratory symptoms some years after treatment completion, including breathlessness and chronic cough [62, 63]. These symptoms can be stigmatizing and lead to repeated investigation or perhaps empirical re-treatment for suspected recurrent tuberculosis disease $[64,65]$. The frequency and severity of respiratory exacerbations among those with residual structural and physiological abnormalities are poorly described, but many face reduced quality of life and impaired functional capacity [66], and those with extensive PTLD and destroyed lung tissue experience high rates of hospitalization and respiratory-related mortality [67].

Post-Tuberculosis Lung Disease time. Early life insults can cause de-tracking of lung function. We hypothesize that tuberculosis disease early in life might cause detracking of lung function, which might remain diminished throughout childhood. This could mean that these individuals will be prone to symptomatic respiratory disease earlier in life. FEV1, forced expiratory volume in $1 \mathrm{~s}$.

Adults previously treated for tuberculosis in high tuberculosis-burden settings have an increased risk of developing incident tuberculosis, compared to those who are tuberculosis naive, including both disease relapse and recurrence [68]. The extent to which this is driven by underlying impaired immune function in damaged lung tissue or underlying socioeconomic risk factors and sustained increased exposure also remains unclear [69]. Although population-level data suggest increased mortality among tuberculosis survivors compared to tuberculosisnaive adults [5-7], the extent to which PTLD contributes to this excess mortality remains unclear.

\section{Risk Factors for PTLD}

As described above, reasons for the heterogeneity of pattern and severity of PTLD between tuberculosis patients are not known, but likely involve host, pathogen, and environmental factors [13]. Investigation of these risk factors is ongoing. HIV co-infection is anticipated as a key effect-modifier in the relationship between tubercu- 
losis disease and residual lung damage, and the extent of PTLD in HIV co-infected patients likely reflects a balance of the protective effect of low CD4 counts and impaired immune responses to mycobacterial infection at tuberculosis diagnosis [70-72], with the impact of immune reconstitution for those initiated on antiretroviral therapy concurrently with tuberculosis treatment [13]. Preliminary findings suggest that HIV co-infection may be associated with reduced severity of PTLD $[14,73]$, but these data are limited and require confirmation in further studies.

More severe lung damage is observed in the context of multidrug-resistant tuberculosis [74, 75], with recurrent episodes of disease [72], and where tuberculosis diagnosis is delayed $[70,71,76]$. The influence of concurrent respiratory exposures is less clear. Tobacco smoking has been shown to have a positive association with PTLD in few studies [72, 77]. Environmental factors such as indoor air pollution or occupational risks and their distribution in the respective populations may worsen PTLD and/or may lead to concurrent lung damage, thereby explaining the severity, heterogeneity, and inconsistency of respiratory outcome data, which were observed in specific subgroups such as females $[71,73]$ and miners $[72,76]$.

\section{Management}

The lack of clinical intervention studies in this patient population means that there are currently no evidencebased international guidelines for the management of PTLD [1]. This represents a challenge for both treating clinicians and patients who experience persistent and disabling respiratory symptoms despite mycobacteriological cure. While evidence-driven guidelines are urgently needed, expert opinions must be sought to bridge the management gap. We discuss below some of the treatment options available and identify the (many) gaps in the published literature to date.

\section{Tuberculosis Disease Prevention}

Undoubtedly, the most important step in the management of PTLD should be its prevention. Where possible, providing prophylactic tuberculosis treatment to those people with latent infection at high risk of progression to disease including household contacts and people living with HIV [78] has potential benefits for population lung health as well as tuberculosis control. The upstream social determinants of tuberculosis disease must also be addressed. Studies evaluating the impact of such interven- tions should evaluate impact on residual lung pathology as well as their effect on reducing TB-related mortality.

\section{Minimising Tuberculosis-Related Lung Damage}

Once tuberculosis disease is established, early diagnosis and effective treatment are crucial for limiting the lung damage caused [21]. Delayed diagnosis and longer disease durations in multidrug-resistant tuberculosis are likely important factors in the observed greater pulmonary function impairment in drug-resistant compared to drug-susceptible tuberculosis [79].

Smoking cessation interventions have proven efficacy for asthma and COPD. In a non-randomized study from Malaysia, tuberculosis patients who received smoking cessation advice and nicotine replacement therapy had earlier sputum smear conversion and better quit rates and treatment outcomes at 6 months [80]. Even though no specific study for the PTLD population exists, smoking cessation should be an integral part in the management of PTLD.

Because excessive inflammation may contribute to lung damage, corticosteroids during tuberculosis treatment have been hypothesized to reduce lung function loss. However, among 118 patients with pulmonary tuberculosis given systemic corticosteroids in addition to tuberculosis treatment, there was no change in airflow obstruction at 1 year follow-up, compared to tuberculosis treatment alone [81]. Thus, corticosteroids cannot be advocated for. Given the broad immunosuppressive action of steroids and their adverse metabolic and cardiovascular effects, a more precise method of immunomodulation may still hold promise. Preliminary studies show that metformin use among patients on tuberculosis treatment resulted in a reduction to the levels of MMP 1, 2, 3, 9, and 12 , which correlate to the degree of pulmonary involvement and degree of cavity formation [82]. To date, there are no randomized trials that assess lung function outcomes following the use of metformin among patients with pulmonary tuberculosis; however, other host-directed therapies are underway.

\section{Managing Established PTLD}

For those with established PTLD, treatments that are widely used for other chronic lung diseases such as COPD, bronchiectasis, asthma, and pulmonary fibrosis may be of benefit; however, specific evidence in PTLD remains lacking. Outpatient pulmonary rehabilitation has been shown to be widely accepted by patients and results in improved symptom scores and health-related quality of life in tuberculosis survivors [83]. 
Inhaled bronchodilators may be useful in the management of PTLD in patients with airflow obstruction to reduce symptoms of breathlessness and improve (or prevent) a decline in lung function. However, there are no long-term randomised trials to inform efficacy, effect size, or medication choice. A single randomized trial of PTLD patients with moderately severe disease found that daily use of the long-acting beta agonist inhaler, indacaterol (dose $150 \mu \mathrm{g}$ ), resulted in a significant improvement in lung function (trough FEV1) and dyspnoea score at 8 weeks compared to placebo, but no improvement in quality of life was achieved [84]. A smaller, non-randomized study demonstrated significant improvements in lung function from baseline among tuberculosis survivors with destroyed lung and FEV $1<80 \%$ who received the long-acting muscarinic antagonists $18 \mu \mathrm{g}$ tiotropium for 2 months, but no quality of life measure was studied [85]. Thus, there is currently no sufficient evidence to generally recommend bronchodilators in PTLD.

Inhaled corticosteroids may be associated with an increased risk of mycobacterial disease when used among tuberculosis survivors (including re-infection or relapse) [86-88]. Inhaled steroids may also alter the respiratory microbiome and increase the risk of non-tuberculous infections and the rate of "exacerbations" [89]. Currently, there are insufficient data to support their use, and they should probably be avoided until evidence emerges.

Clinical challenges in the management of post-tuberculosis bronchiectasis include prophylaxis and treatment of bacterial and fungal infection complications. Since management strategies specifically for post-tuberculosis bronchiectasis do not exist, recommendations developed for non-CF bronchiectasis [90] may be applied. The mainstay of therapy in the context of structural lung disease is to avoid the vicious cycle of impaired mucociliary clearance, chronic infection, and inflammation, leading to further structural lung damage [90]. The presence or absence of infection with Pseudomonas aeruginosa determines if - after exclusion of additional non-tuberculous mycobacterial infection - long-term macrolide treatment or long-term inhaled antibiotic treatment is preferred. If $P$. aeruginosa is isolated for the first time, eradication treatment should be given. However, evidence for antipseudomonal strategies in PTLD and LMICs remains unclear and may be challenging due to inherent resource limitation. Short- or long-acting bronchodilators, mucolytic (hypertonic saline), and regular airway clearance are beneficial in non-CF bronchiectasis, especially if patients have difficulty with sputum expectoration and airway clearance.

Post-Tuberculosis Lung Disease
Exacerbations of PTLD are a priority area for research. Little data exist to inform management, or policy decisions, yet exacerbations are likely to both identify individuals at increased risk and those who disproportionally access medical care. As noted above, patients previously treated for tuberculosis are at increased risk of recurrence, and this should be actively excluded with exacerbations. However, exacerbations of PTLD are frequently and erroneously re-treated with empiric treatment for "recurrent tuberculosis" without microbiological evidence, exposing patients to harm [65]. Adding complexity, Xpert nucleic amplification tests yield a $14 \%$ ( 1 in 7 ) false-positive rate in re-treatment cases and may remain positive for years after successful tuberculosis treatment completion [91]. Thus, decisions on initiating tuberculosis re-treatment can be difficult and should be made in conjunction with a careful history, physical examination, and sputum microscopy and culture (if possible), with planned review at 4-6 weeks.

Fungal disease and haemoptysis are characterized by non-specific clinical presentation, and the diagnosis may be delayed. In chest CT, an early pulmonary nodule, a "halo sign," defined by a ground-glass opacity around a nodule, or fungal balls in a pre-existing cavity are classical presentations of CPA. The diagnosis is supported by fungal elements in bronchoalveolar lavage or by the presence of galactomannan or beta-D-glycan. Serum Aspergillus precipitins are more sensitive and appear to correlate with disease activity [92]. CPA is associated with a high morbidity and mortality [41], and it has been recognized that the presence of Aspergillus Ig G and Ig M antibodies predisposes to haemoptysis complications [93]. Unfortunately, availability of diagnostic tests can be challenging in LMICs, where the highest prevalence is anticipated. The recommended first-line treatment of choice for invasive CPA is voriconazole with therapeutic drug monitoring $[38,39]$. Antifungal therapy leads to improvement in symptoms and radiological findings, but relapses after several months of treatment are common, and life-long therapy may be necessary [41]. Other recommended antifungal agents include itraconazole and posaconazole, while intravenous liposomal amphotericin B and caspofungin are less effective and more complicated to apply, and fluconazole has no anti-Aspergillus activity. Surgery with resection of cavity and aspergilloma offers a chance for cure in operable patients with a solitary lesion. Symptomatic patients with a simple aspergilloma can be managed with surgery alone, but in more complex cases, preand postoperative antifungal therapies are recommended for at least 2 months. Surgery is also a last-line therapy in CPA-associated major haemoptysis [41]. However, in 
daily practice in LMICs with a high PTLD burden, many of these therapeutic and surgical options are either unavailable or unaffordable, limiting clinician's choices.

Major haemoptysis, defined by a loss of 300-600 mL of blood within $24 \mathrm{~h}$ and/or blood causing airway obstruction, is a major life-threatening emergency [94]. It is not only a well-known and feared complication of active pulmonary tuberculosis and of chronic bronchiectasis of any cause, but often the presenting syndrome of an unrecognized CPA. Under these circumstances, clinicians frequently use bronchial artery embolization to address active bleeding, although recurrence is common $[95,96]$. Other interventional or complex surgical options have also been applied with good results $[97,98]$. Unfortunately, for many patients with PTLD-associated haemoptysis, surgical resection is not an option due to either the overwhelming extent of disease or poor physiological reserve.

For now, it seems reasonable that, as in other forms of chronic lung diseases, smoking cessation, vaccination, and pulmonary rehabilitation should be considered in a PTLD management plan. However, well-designed randomized trials are urgently required to identify feasible and scalable interventions to improve the outcomes of PTLD patients. In order for these trials to move forward, consensus is needed on how patterns and severity of PTLD are defined, how disease is measured, and outcomes to be evaluated over time.

\section{Economic, Social, and Psychological Impact}

It is well known that tuberculosis is driven by poverty and is associated with a catastrophic financial burden on affected, mostly low-income, households [99]. High patient costs not only worsen the financial situation of households but also negatively influence tuberculosis treatment outcomes [100]. The need to mitigate catastrophic costs associated with tuberculosis disease has been prioritized within The End TB agenda. People cured of tuberculosis may find themselves with long-term socio-psychological consequences of the acute disease episode, and PTLD may result in ongoing economic, social, and psychological distress. However, data on these impacts of tuberculosis, beyond treatment completion, remain limited and their impact on long-term well-being is poorly defined.

There are currently no recommendations for the evaluation of mental or health-related quality of life in people beyond tuberculosis treatment. There is limited evidence that people who are microbiologically cured of tuberculosis have substantially lower health-related quality of life compared to those with similar pulmonary risk factors or healthy controls [30, 100-103]. Preliminary modelling data suggest that inclusion of post-tuberculosis morbidity and mortality may increase estimates of disability-adjusted life years by at least $54 \%$ (and potentially as much as $174 \%$ ), when permanent disability and early mortality are also considered [69]. Further, social stressors such as discrimination and stigma are common among people with tuberculosis and increasingly recognized as factors that compromise mental health, quality of life, and tuberculosis treatment outcomes long term $[2,3,104]$. There is an urgent need for robust epidemiological and large multi-country cohort studies on the economic and psychosocial impact beyond tuberculosis cure.

\section{Future and Conclusion}

It is true to say that currently we have more questions than answers around PTLD, its determinants, natural history, and management. Yet in recent years, there has been an expansion of interest in this complex condition, with the realization that the high prevalence of PTLD in LMICs, where $80 \%$ of the world's population resides, may in fact make it an extremely important form of chronic lung disease and respiratory impairment worldwide.

Several priority research areas have been identified. First, epidemiological research is needed to better define the risk factors and predictors for PTLD, as well as longterm functional outcomes, and most importantly causes and predictors of the observed premature mortality in tuberculosis survivors. This includes the burden and nature of PTLD in children, and its long-term effects on the individual's lung health throughout life. Second, a better understanding of the immunological drivers of PTLD is needed, combined with prevention and host-directed strategies during treatment, to avoid or minimize damage during tuberculosis disease. Third, research into effective treatment of the various PTLD phenotypes is urgently needed, for those with established PTLD in whom primary prevention is too late. Finally, it must be remembered that PTLD is only one of many complications after tuberculosis, which significantly affects the economic, social, and psychological well-being of individuals, families, and societies. This broader impact needs to be defined with a view to designing effective intervention strategies to minimise this impact.

In conclusion, PTLD, for many decades forgotten, is now being recognised as an important cause of chronic lung disease globally, particularly in LMICs. While there
Allwood/Byrne/Meghij/Rachow/ van der Zalm/Schoch 
is an emerging literature on PTLD, collaborative research is urgently needed to inform our understanding of the natural history, prevention, and treatment of PTLD and to allow for the development of much needed evidencebased management guidelines.

\section{Conflict of Interest Statement}

B.W.A. has received honoraria from Novartis. M.M.Z. is part of the EDCTP2 programme supported by the European Union (Grant No. 99726 TB-Lung FACT TMA 2015 CDF - 1012). All other authors have no conflicts of interest to declare.

\section{Funding Sources}

There was no funding related to the preparation of the manuscript.

\section{Author Contributions}

All authors contributed equally to the writing and preparation of the manuscript.

\section{References}

1 van Kampen SC, Wanner A, Edwards M, Harries $\mathrm{AD}$, Kirenga $\mathrm{BJ}$, Chakaya J, et al. International research and guidelines on post-tuberculosis chronic lung disorders: a systematic scoping review. BMJ Glob Health. 2018 Jul; 3(4):e000745.

2 Allwood B, van der Zalm M, Makanda G, Mortimer K, Andre F.S. A, Uzochukwu E, et al. The long shadow post-tuberculosis. Lancet Infect Dis. 2019 Nov;19(11):1170-1.

3 Allwood BW, van der Zalm MM, Amaral AFS, Byrne A, Datta S, Egere U, et al. Posttuberculosis lung health: perspectives from the First International Symposium. Int $\mathrm{J} \mathrm{Tu}$ berc Lung Dis. 2020;24(8):820-8.

4 World Health Organization. Tuberculosis Fact Sheet. [cited 2019 Aug 11]. Available from: https://www.who.int/en/news-room/ fact-sheets/detail/tuberculosis.

5 Romanowski K, Baumann B, Basham CA, Ahmad Khan F, Fox GJ, Johnston JC. Longterm all-cause mortality in people treated for tuberculosis: a systematic review and metaanalysis. Lancet Infect Dis. 2019 Oct;19(10): 1129-37.

6 Miller TL, Wilson FA, Pang JW, Beavers S, Hoger S, Sharnprapai S, et al. Mortality hazard and survival after tuberculosis treatment. Am J Public Health. 2015 May;105(5):930-7.

7 Ranzani OT, Rodrigues LC, Bombarda S, Minto CM, Waldman EA, Carvalho CRR. Long-term survival and cause-specific mortality of patients newly diagnosed with tuberculosis in São Paulo state, Brazil, 2010-15: a population-based, longitudinal study. Lancet Infect Dis. 2020 Jan;20(1):123-32.

8 Amaral AF, Coton S, Kato B, Tan WC, Studnicka $\mathrm{M}$, Janson $\mathrm{C}$, et al. Tuberculosis associates with both airflow obstruction and low lung function: BOLD results. Eur Respir J. 2015;46(4):1104-12.

9 Menezes AM, Hallal PC, Perez-Padilla R, Jardim JR, Muiño A, Lopez MV, et al. Tuberculosis and airflow obstruction: evidence from the PLATINO study in Latin America. Eur Respir J. 2007 Aug;30(6):1180-5.
10 Allwood BW, Myer L, Bateman ED. A systematic review of the association between pulmonary tuberculosis and the development of chronic airflow obstruction in adults. Respiration. 2013;86(1):76-85.

11 Byrne AL, Marais BJ, Mitnick CD, Lecca L, Marks GB. Tuberculosis and chronic respiratory disease: a systematic review. Int J Infect Dis. 2015;32:138-46.

12 Muñoz-Torrico $M$, Rendon A, Centis R, D’Ambrosio L, Fuentes Z, Torres-Duque C, et al. Is there a rationale for pulmonary rehabilitation following successful chemotherapy for tuberculosis? J Bras Pneumol. 2016 Sep;42(5): 374-85.

13 Ravimohan S, Kornfeld H, Weissman D, Bisson GP. Tuberculosis and lung damage: from epidemiology to pathophysiology. Eur Respir Rev. 2018 Mar;27(147):170077.

14 Meghji J, Lesosky M, Joekes E, Banda P, Rylance J, Gordon S, et al. Patient outcomes associated with post-tuberculosis lung damage in Malawi: a prospective cohort study. Thorax. 2020 Mar;75(3):269-78.

15 Khosa C, Bhatt N, Massango I, Azam K, Saathoff E, Bakuli A, et al. Development of chronic lung impairment in Mozambican TB patients and associated risks. BMC Pulm Med. 2020 May;20(1):127.

16 Allwood BW, Maasdorp E, Kim GJ, Cooper $\mathrm{CB}$, Goldin J, van Zyl-Smit RN, et al. Transition from restrictive to obstructive lung function impairment during treatment and follow-up of active tuberculosis. Int $\mathrm{J}$ Chron $\mathrm{Ob}$ struct Pulmon Dis. 2020 May;15:1039-47.

17 Stek C, Allwood B, Walker NF, Wilkinson RJ, Lynen L, Meintjes G. The immune mechanisms of lung parenchymal damage in tuberculosis and the role of host-directed therapy. Front Microbiol. 2018 Oct; 9:2603.

18 de Martino M, Lodi L, Galli L, Chiappini E. Immune response to Mycobacterium tuberculosis: a narrative review. Front Pediatr. 2019 Aug; 7:350.

19 Flynn JL, Chan J. Tuberculosis: latency and reactivation. Infect Immun. $2001 \mathrm{Apr} ; 69(7)$ : 4195-201.
20 Ulrichs T, Kaufmann SH. New insights into the function of granulomas in human tuberculosis. J Pathol. 2006 Jan;208(2):261-9.

21 Lee CH, Lee MC, Lin HH, Shu CC, Wang JY, Lee LN, et al. Pulmonary tuberculosis and delay in anti-tuberculous treatment are important risk factors for chronic obstructive pulmonary disease. PLoS One. 2012 May;7(5): e37978.

22 Davis JM, Ramakrishnan L. The role of the granuloma in expansion and dissemination of early tuberculous infection. Cell. 2009 Jan; 136(1):37-49.

23 Tobin DM, Roca FJ, Oh SF, McFarland R, Vickery TW, Ray JP, et al. Host genotype-specific therapies can optimize the inflammatory response to mycobacterial infections. Cell. 2012 Feb;148(3):434-46.

24 Kübler A, Luna B, Larsson C, Ammerman NC, Andrade BB, Orandle M, et al. Mycobacterium tuberculosis dysregulates MMP/ TIMP balance to drive rapid cavitation and unrestrained bacterial proliferation. J Pathol. 2015 Feb;235(3):431-44.

25 Menezes AM, Perez-Padilla R, Jardim JR, Muiño A, Lopez MV, Valdivia G, et al. Chronic obstructive pulmonary disease in five Latin American cities (the PLATINO study): a prevalence study. Lancet.2005 Dec;366(9500): 1875-81.

26 Caballero A, Torres-Duque CA, Jaramillo C, Bolívar F, Sanabria F, Osorio P, et al. Prevalence of COPD in five Colombian cities situated at low, medium, and high altitude (PREPOCOL Study). Chest. 2008 Feb;133(2):3439.

27 Lam KB, Jiang CQ, Jordan RE, Miller MR Zhang WS, Cheng KK, et al. Prior TB, Smoking, and airflow obstruction : a cross-sectional analysis of the Guangzhou Biobank Cohort Study. Chest. 2010;137(3):593-600.

28 Allwood BW, Rigby J, Griffith-Richards S, Kanarek D, Du Preez L, Mathot B, et al. Histologically confirmed tuberculosis-associated obstructive pulmonary disease. Int J Tuberc Lung Dis. 2019;23(5):552-4. 
29 Ehrlich RI, Adams S, Baatjies R, Jeebhay MF. Chronic airflow obstruction and respiratory symptoms following tuberculosis: a review of South African studies. Int J Tuberc Lung Dis. 2011 Jul;15(7):886-91.

30 Pasipanodya JG, Miller TL, Vecino M, Munguia G, Garmon R, Bae S, et al. Pulmonary impairment after tuberculosis. Chest. 2007; 131(6):1817-24.

31 Chung KP, Chen JY, Lee CH, Wu HD, Wang JY, Lee LN, et al. Trends and predictors of changes in pulmonary function after treatment for pulmonary tuberculosis. Clinics. 2011;66(4):549-56.

32 Meghji J, Simpson H, Squire SB, Mortimer K A systematic review of the prevalence and pattern of imaging defined post-TB lung disease. PLoS One. 2016 Aug;11(8):e0161176.

33 Panda A, Bhalla AS, Sharma R, Mohan A, Sreenivas V, Kalaimannan U, et al. Correlation of chest computed tomography findings with dyspnea and lung functions in post-tubercular sequelae. Lung India. 2016 Nov; 33(6):592.

34 Malherbe ST, Shenai S, Ronacher K, Loxton AG, Dolganov G, Kriel M, et al. Persisting positron emission tomography lesion activity and Mycobacterium tuberculosis mRNA after tuberculosis cure. Nat Med. 2016;22(10): 1094-100.

35 Ordonez AA, Wang H, Magombedze G, RuizBedoya CA, Srivastava S, Chen A, et al. Dynamic imaging in patients with tuberculosis reveals heterogeneous drug exposures in pulmonary lesions. Nat Med. 2020 Apr;26(4): 529-34.

36 Akkara SA, Shah AD, Adalja M, Akkara AG, Rathi A, Shah DN. Pulmonary tuberculosis: the day after. Int J Tuberc Lung Dis. 2013; 17(6):810-3.

37 Ahmed AE, Ibrahim AS, Elshafie SM. Pulmonary hypertension in patients with treated pulmonary tuberculosis: analysis of 14 consecutive cases. Clin Med Insights Circ Respir Pulm Med. 2011 Jan;5:1-5.

38 Segal BH. Aspergillosis. N Engl J Med. 2009 Apr;360(18):1870-84.

39 Kosmidis C, Denning DW. The clinical spectrum of pulmonary aspergillosis. Thorax. 2015 Mar;70(3):270-7.

40 Denning DW, Pleuvry A, Cole DC. Global burden of chronic pulmonary aspergillosis as a sequel to pulmonary tuberculosis. Bull World Health Organ. 2011 Dec;89(12):86472.

41 Alastruey-Izquierdo A, Cadranel J, Flick H, Godet C, Hennequin C, Hoenigl M, et al. Treatment of chronic pulmonary aspergillosis: current standards and future perspectives. Respiration. 2018 Aug;96(2):159-70.

42 Dhooria S, Kumar P, Saikia B, Aggarwal AN, Gupta D, Behera D, et al. Prevalence of Aspergillus sensitisation in pulmonary tuberculosis-related fibrocavitary disease. Int $J$ Tuberc Lung Dis. 2014 Jul;18(7):850-5.
43 Denning DW, Cadranel J, Beigelman-Aubry C, Ader F, Chakrabarti A, Blot S, et al. Chronic pulmonary aspergillosis: rationale and clinical guidelines for diagnosis and management. Eur Respir J. 2016 Jan;47(1):45-68.

44 Seddon JA, Chiang SS, Esmail H, Coussens AK. The wonder years: what can primary school children teach us about immunity to Mycobacterium tuberculosis? Front Immunol. 2018 Dec;9:2946.

45 Roya-Pabon CL, Perez-Velez CM. Tuberculosis exposure, infection and disease in children: a systematic diagnostic approach. Pneumonia. 2016 Dec;8(1):23.

46 Dodd PJ, Gardiner E, Coghlan R, Seddon JA. Burden of childhood tuberculosis in 22 highburden countries: a mathematical modelling study. Lancet Glob Health. 2014 Aug;2(8): e453-9.

47 Frigati L, Bekker A, Stroebele S, Goussard P, Schaaf HS. Culture-confirmed tuberculosis in South African infants younger than 3 months of age: clinical presentation and management of respiratory complications. Pediatr Infect Dis J. 2019 Apr;38(4):351-4.

48 Vanden Driessche K, Persson A, Marais BJ, Fink PJ, Urdahl KB. Immune vulnerability of infants to tuberculosis. Clin Dev Immunol. 2013;2013:781320-16.

49 Stocks J, Hislop A, Sonnappa S. Early lung development: lifelong effect on respiratory health and disease. Lancet Respir Med. 2013 Nov; 1(9):728-42.

50 Merkus PJ, ten Have-Opbroek AA, Quanjer PH. Human lung growth: a review. Pediatr Pulmonol. 1996 Jun;21(6):383-97.

51 Narayanan M, Owers-Bradley J, Beardsmore CS, Mada M, Ball I, Garipov R, et al. Alveolarization continues during childhood and adolescence: new evidence from helium-3 magnetic resonance. Am J Respir Crit Care Med. 2012 Jan;185(2):186-91.

52 Twisk JW, Staal BJ, Brinkman MN, Kemper HC, Van Mechelen W. Tracking of lung function parameters and the longitudinal relationship with lifestyle. Eur Respir J. 1998 Sep; 12(3):627-34.

53 Kallapur SG, Ikegami M. Physiological consequences of intrauterine insults. Paediatr Respir Rev. 2006 Jun;7(2):110-6.

54 Stern DA, Morgan WJ, Wright AL, Guerra S, Martinez FD. Poor airway function in early infancy and lung function by age 22 years: a non-selective longitudinal cohort study. Lancet. 2007 Sep;370(9589):758-64.

55 Chan JY, Stern DA, Guerra S, Wright AL, Morgan WJ, Martinez FD. Pneumonia in childhood and impaired lung function in adults: a longitudinal study. Pediatrics. 2015 Apr;135(4):607-16.

56 Gray DM, Turkovic L, Willemse L, Visagie A, Vanker A, Stein DJ, et al. Lung function in African infants in the Drakenstein Child Health Study. Impact of lower respiratory tract illness. Am J Respir Crit Care Med. 2017 Jan;195(2):212-20.
57 Fauroux B, Simões EAF, Checchia PA, Paes B, Figueras-Aloy J, Manzoni P, et al. The burden and long-term respiratory morbidity associated with respiratory syncytial virus infection in early childhood. Infect Dis Ther. 2017 Jun; 6(2):173-97.

58 Githinji LN, Gray DM, Hlengwa S, Machemedze T, Zar HJ, Zar HJ. Longitudinal changes in spirometry in South African adolescents perinatally infected with human immunodeficiency virus who are receiving antiretroviral therapy. Clin Infect Dis. 2020 Jan; 70(3):483-90.

59 Marais BJ, Gie RP, Schaaf HS, Hesseling AC, Obihara CC, Starke JJ, et al. The natural history of childhood intra-thoracic tuberculosis: a critical review of literature from the pre-chemotherapy era. Int J Tuberc Lung Dis. 2004; 8(4):392-402.

60 Marais BJ, Gie RP, Schaaf HS, Hesseling AC, Enarson DA, Beyers N. The spectrum of disease in children treated for tuberculosis in a highly endemic area. Int J Tuberc Lung Dis. 2006;10(7):732-8.

61 Duong ML, Islam S, Rangarajan S, Leong D, Kurmi O, Teo K, et al. Mortality and cardiovascular and respiratory morbidity in individuals with impaired FEV 1 (PURE): an international, community-based cohort study. Lancet Glob Health. 2019 May;7(5):e613-23.

62 Banu Rekha VV, Ramachandran R, Kuppu Rao KV, Rahman F, Adhilakshmi AR, Kalaiselvi D, et al. Assessment of long term status of sputum positive pulmonary TB patients successfully treated with short course chemotherapy. Indian J Tuberc. 2009 Jul;56(3):132-40.

63 Ehrlich RI, White N, Norman R, Laubscher R, Steyn K, Lombard C, et al. Predictors of chronic bronchitis in South African adults. Int J Tuberc Lung Dis. 2004;8(3):369-76.

64 Chikovore J, Hart G, Kumwenda M, Chipungu G, Desmond N, Corbett EL. TB and HIV stigma compounded by threatened masculinity: Implications for TB health-care seeking in Malawi. Int J Tuberc Lung Dis. 2017 Nov; 21(11):26-33.

65 Metcalfe JZ, Mason P, Mungofa S, Sandy C, Hopewell PC. Empiric tuberculosis treatment in retreatment patients in high HIV/tuberculosis-burden settings. Lancet Infect Dis. 2014; 14(9):794-5.

66 Pasipanodya JG, Miller TL, Vecino M, Munguia G, Bae S, Drewyer G, et al. Using the St. George respiratory questionnaire to ascertain health quality in persons with treated pulmonary tuberculosis. Chest. 2007;132(5):1591-8.

67 Ryu YJ, Lee JH, Chun EM, Chang JH, Shim SS. Clinical outcomes and prognostic factors in patients with tuberculous destroyed lung. Int J Tuberc Lung Dis. 2011;15(2):246-i.

68 Marx FM, Floyd S, Ayles H, Godfrey-Faussett P, Beyers N, Cohen T. High burden of prevalent tuberculosis among previously treated people in Southern Africa suggests potential for targeted control interventions. Eur Respir J. 2016;48(4):1227-30. 
69 Quaife M, Houben RMGJ, Allwood B, Cohen T, Coussens AK, Harries AD, et al. Post-tuberculosis mortality and morbidity: valuing the hidden epidemic. Lancet Respir Med. 2020 Apr;8(4):332-3.

70 Ralph AP, Kenangalem E, Waramori G, Pontororing GJ, Sandjaja, Tjitra E, et al. High morbidity during treatment and residual pulmonary disability in pulmonary tuberculosis: under-recognised phenomena. PLoS One. 2013;8(11):e80302-11.

71 Fiogbe AA, Agodokpessi G, Tessier JF, Affolabi D, Zannou DM, Adé G, et al. Prevalence of lung function impairment in cured pulmonary tuberculosis patients in Cotonou, Benin. Int J Tuberc Lung Dis. 2019;23(2):195-202.

72 Hnizdo E, Singh T, Churchyard G. Chronic pulmonary function impairment caused by initial and recurrent pulmonary tuberculosis following treatment. Thorax. $2000 \mathrm{Jan} ; 55(1)$ : 32-8.

73 Manji M, Shayo G, Mamuya S, Mpembeni R, Jusabani A, Mugusi F. Lung functions among patients with pulmonary tuberculosis in Dar es Salaam: a cross-sectional study. BMC Pulm Med. 2016 Dec;16(1):58.

74 de Vallière S, Barker RD. Residual lung damage after completion of treatment for multidrug-resistant tuberculosis. Int J Tuberc Lung Dis. 2004 Jun;8(6):767-71.

75 Singla N, Singla R, Fernandes S, Behera D. Post treatment sequelae of multi-drug resistant tuberculosis patients. Indian J Tuberc. 2009;56(4):206-12.

76 Ross J, Ehrlich RI, Hnizdo E, White N, Churchyard GJ. Excess lung function decline in gold miners following pulmonary tuberculosis. Thorax. 2010 Nov;65(11):1010-5.

77 Plit ML, Anderson R, Van Rensburg CE, Page-Shipp L, Blott JA, Fresen JL, et al. Influence of antimicrobial chemotherapy on spirometric parameters and pro-inflammatory indices in severe pulmonary tuberculosis. Eur Respir J. 1998;12(2):351-6.

78 World Health Organization. WHO|Latent TB Infection: Updated and consolidated guidelines for programmatic management [Internet]. WHO. 2019 [cited 2020 Jun 23]. Available from: http://www.who.int/tb/publications/2018/latent-tuberculosis-infection/en/.

79 Byrne AL, Marais BJ, Mitnick CD, Garden FL, Lecca L, Contreras C, et al. Chronic airflow obstruction after successful treatment of multidrug-resistant tuberculosis. ERJ Open Res. 2017 Jul;3(3):

80 Awaisu A, Nik Mohamed MH, Mohamad Noordin N, Abd Aziz N, Syed Sulaiman SA, Muttalif AR, et al. The SCIDOTS Project: evidence of benefits of an integrated tobacco cessation intervention in tuberculosis care on treatment outcomes. Subst Abuse Treat Prey Policy. 2011 Sep;6(1):26.
81 Malik SK, Martin CJ. Tuberculosis, corticosteroid therapy, and pulmonary function. Am Rev Respir Dis. 1969 Jul;100(1):13-8.

82 Kumar NP, Moideen K, Viswanathan V, Shruthi BS, Sivakumar S, Menon PA, et al. Elevated levels of matrix metalloproteinases reflect severity and extent of disease in tuberculosis-diabetes co-morbidity and are predominantly reversed following standard anti-tuberculosis or metformin treatment. BMC Infect Dis. 2018 Jul;18(1):345.

83 Visca D, Zampogna E, Sotgiu G, Centis R, Saderi L, D'Ambrosio L, et al. Pulmonary rehabilitation is effective in patients with tuberculosis pulmonary sequelae. Eur Respir J. 2019 Mar;53(3):1802184

84 Kim CJ, Yoon HK, Park MJ, Yoo KH, Jung KS, Park JW, et al. Inhaled indacaterol for the treatment of COPD patients with destroyed lung by tuberculosis and moderate-to-severe airflow limitation: results from the randomized INFINITY study. Int J Chron Obstruct Pulmon Dis. 2017;12:1589-96.

85 Yum HK, Park IN. Effect of inhaled tiotropium on spirometric parameters in patients with tuberculous destroyed lung. Tuberc Respir Dis. 2014;77(4):167-71.

86 Dong YH, Chang CH, Wu FL, Shen LJ, Calverley PMA, Löfdahl CG, et al. Use of inhaled corticosteroids in patients with COPD and the risk of TB and influenza: a systematic review and meta-analysis of randomized controlled trials. a systematic review and metaanalysis of randomized controlled trials. Chest. 2014 Jun;145(6):1286-97.

87 Brassard P, Suissa S, Kezouh A, Ernst P. Inhaled corticosteroids and risk of tuberculosis in patients with respiratory diseases. Am J Respir Crit Care Med. 2011;183(5):675-8.

$88 \mathrm{Ni} \mathrm{S}, \mathrm{Fu}$ Z, Zhao J, Liu H. Inhaled corticosteroids (ICS) and risk of mycobacterium in patients with chronic respiratory diseases: a meta-analysis. J Thorac Dis. 2014;6(7):971-8.

89 Contoli M, Pauletti A, Rossi MR, Spanevello A, Casolari P, Marcellini A, et al. Long-term effects of inhaled corticosteroids on sputum bacterial and viral loads in COPD. Eur Respir J. 2017 Oct;50(4):1700451.

90 Polverino E, Goeminne PC, McDonnell MJ, Aliberti S, Marshall SE, Loebinger MR, et al. European Respiratory Society guidelines for the management of adult bronchiectasis. Eur Respir J. 2017 Sep;50(3):1700629.

91 Theron G, Venter R, Calligaro G, Smith L, Limberis J, Meldau R, et al. Xpert MTB/RIF results in patients with previous tuberculosis: can we distinguish true from false positive results? Clin Infect Dis. 2016;62(8):995-1001.

92 Schweer KE, Bangard C, Hekmat K, Cornely OA. Chronic pulmonary aspergillosis. Mycoses. 2014 May;57(5):257-70.
93 Chu CM, Woo PC, Chong KT, Leung WS, Chan VL, Yuen KY. Association of presence of Aspergillus antibodies with hemoptysis in patients with old tuberculosis or bronchiectasis but no radiologically visible mycetoma. J Clin Microbiol. 2004 Feb;42(2):665-9.

94 Jin F, Li Q, Bai C, Wang H, Li S, Song Y, et al. Chinese expert recommendation for diagnosis and treatment of massive hemoptysis. Respiration. 2020 Jan;99(1):83-92.

95 Panda A, Bhalla AS, Goyal A. Bronchial artery embolization in hemoptysis: a systematic review. Diagn Interv Radiol. 2017 Jul;23(4): 307-17.

96 Peng Y, Zhu Y, Ao G, Chen Z, Yuan X, Li Q, et al. Effect of bronchial artery embolisation on the management of tuberculosis-related haemoptysis. Int J Tuberc Lung Dis. 2019 Dec; 23(12):1269-76.

97 Lalla U, Allwood BW, Sinha Roy S, Irusen EM, Koegelenberg CFN. Endobronchial valve used as salvage therapy in a mechanically ventilated patient with intractable life-threatening haemoptysis. Respiration. 2017 May; 93(6):436-40.

98 Giang NT, Dung LT, Hien NT, Thiet TT, Hiep PS, Vu NT, et al. Hemoptysis from complex pulmonary aspergilloma treated by cavernostomy and thoracoplasty. BMC Surg. 2019 Dec 19(1):187.

99 Boccia D, Bond V. The catastrophic cost of tuberculosis: advancing research and solutions. Int J Tuberc Lung Dis. 2019 Nov;23(11): 1129-30.

100 Wingfield T, Boccia D, Tovar M, Gavino A, Zevallos K, Montoya R, et al. Defining catastrophic costs and comparing their importance for adverse tuberculosis outcome with multi-drug resistance: a prospective cohort study, Peru. PLoS Med. 2014 Jul;11(7): e1001675.

101 Vecino M, Munguia G, Bae S, Weis SE, Drewyer G, Pasipanodya JG, et al. Using the St. George respiratory questionnaire to ascertain health quality in persons with treated pulmonary tuberculosis. Chest. 2007;132(5):1591-8.

102 Guo N, Marra F, Marra CA. Measuring health-related quality of life in tuberculosis: a systematic review. Health Qual Life Outcomes. 2009 Feb;7(1):14.

103 Daniels KJ, Irusen E, Pharaoh H, Hanekom S Post-tuberculosis health-related quality of life, lung function and exercise capacity in a cured pulmonary tuberculosis population in the Breede Valley District, South Africa. S Afr J Physiother. 2019 Jul;75(1):a1319.

104 Rachow A, Ivanova O, Wallis R, Charalambous $\mathrm{S}$, Jani I, Bhatt N, et al. TB sequel: incidence, pathogenesis and risk factors of longterm medical and social sequelae of pulmonary TB: a study protocol. BMC Pulm Med. 2019 Dec;19(1):4 